\title{
ANALISIS SIFAT TARIK DAN IMPAK KOMPOSIT SERAT RAMI DENGAN PERLAKUAN ALKALI DALAM WAKTU 2, 4, 6, DAN 8 JAM BERMATRIK POLIESTER
}

\author{
Pramuko Ilmu Purboputro, Agus Hariyanto \\ Teknik Mesin Universitas Muhamadiyah Surakarta \\ J1. A. Yani Tromol Pos I Pabelan, Kartasura \\ Email:pip272@ums.ac.id
}

\begin{abstract}
ABSTRAK
Ikatan interfacal bonding pada komposit serat alam sangat tergantung dari kekasaran permukaan serat. Permukaan serat dapat ditingkatkan daya ikatan permukaannya dengan cara mencelupkan pada larutan alkali. Pencelupan ini akan mengurangi lapisan lignin yang mengurangi kekuatan ikat pada permukaan serat. Pada penelitian ini proses yang digunakan adalah perlakuan alkali terhadap permukaan serat dengan cara merendam serat rami selama 2,4,6, dan 8 jam. Larutah alkali yang digunakan adalah larutan $\mathrm{NaOH}$ dengan konsentrasi $10 \%$ pada pelarut air. Serat rami Boehmeria nivea (L) Goud direndam pada larutan NaOH selama 2, 4, 6, dan 8 jam perendaman, untuk menghilangkan zat ligninnya agar kekuatan ikatan permukaan bisa diperbaiki. Pengujian yang dilakukan adalah pengujian tarik dan pengujian impak. Hasil yang didapat adalah kekuatan tarik terbesar didapat pada perendaman 8 jam yaitu sebesar 41,9 MPa. Modulus young terbesar didapat pada perendaman 2 jam, yaitu 2743,15 Mpa, dan kekuatan impak terbesar adalah 0,0725 Joule $/ \mathrm{mm}^{2}$ terjadi pada perendaman 4 jam.
\end{abstract}

Kata kunci: komposit serat, kekuatan tarik, kekuatan impak, perendaman alkali

\begin{abstract}
The interfacial bonding of natural fiber composites are highly dependent on the roughness of the fiber surface. The surface of the fiber can be enhanced its surface bonding power by dipping in an alkaline solution. This dipping will reduce the lignin layer which reduces the binding strength on the fiber surface. In this study, the used process is the alkali treatment of the surface of the fiber by immersing the ramie fiber for 2, 4, 6, and 8 hours. This study used NaOH solution with a concentration of $10 \%$ in water solvent as Alkali solution. Ramie fiber Boehmeria nivea (L) Goud is soaked in a solution of $\mathrm{NaOH}$ for 2,4,6, and 8 hours of soaking, to remove lignin substances so the surface bond strength can be improved. The performed tests are tensile and impact test. The result is the greatest tensile strength is obtained by 8 hours immersion which is equal to $41.9 \mathrm{MPa}$. The biggest modulus is obtained by 2 hours immersion (2743.15 Mpa) and the biggest impact strength was $0.0725 \mathrm{Joule} / \mathrm{mm}^{2}$ occurred at 4 hours immersion.
\end{abstract}

Keywords: fiber composite, tensile strength, impact strength, alkali immersion 


\section{PENDAHULUAN}

Penggunaan dan pemanfaatan material komposit sekarang ini semakin berkembang, seiring dengan meningkatnya penggunaan bahan tersebut yang semakin meluas mulai dari yang sederhana seperti alat-alat rumah tangga sampai sektor industri baik industri skala kecil maupun industri skala besar. Komposit mempunyai keunggulan tersendiri dibandingkan dengan bahan teknik alternatif lain seperti kuat, ringan, tahan korosi, ekonomis dan sebagainya.

Tanaman rami yang dikenal dengan nama latinnya Boehmeria nivea (L) Goud merupakan tanaman tahunan berbentuk rumpun yang dapat menghasilkan serat alam nabati dari pita (ribbons) pada kulit kayunya yang sangat keras dan mengkilap. Tanaman rami adalah tanaman tahunan yang berbentuk rumpun mudah tumbuh dan dikembangkan di daerah tropis, tahan terhadap penyakit dan hama, serta dapat mendukung pelestarian lingkungan. Dalam hal tertentu serat rami mempunyai keunggulan dibandingkan serat yang lainnya seperti kekuatan tarik, daya serap terhadap air, tahan terhadap kelembapan dan bakteri, tahan terhadap panas serta peringkat nomor dua setelah sutra dibandingkan serat alam yang lainnya dan lebih ringan dibanding serat sintetis dan ramah lingkungan.

Dari pertimbangan tersebut maka penelitian ini dilakukan untuk mendapatkan data tentang kemampuan fisis dan mekanis berupa kekuatan tarik, dan kekuatan impact dari serat rami menggunakan matrik polyester dengan perlakuan alkali $(\mathrm{NaOH})$ serta dibuat dengan hand lay up.

Tujuan dari perlakuan alkali adalah untuk menghilangkan lapisan lignin yang ada di permukaan serat. Dengan menghilangkan lapisan lignin pada permukaan diharapkan ikatan permukaan antar permukaan serat rami dengan matriks akan lebih kuat. Pengambilan waktu pencelupan 2, 4, 6, 8 jam adalah suatu pendekatan waktu yang masih bisa direalisasikan, apabila komposit ini benar-benar akan dibuat secara masal. Selain itu pengambilan waktu tersebut adalah dengan konsentrasi $10 \% \mathrm{NaOH}$ dengan waktu minimal 2 jam akan diperoleh reaksi pada permukaan serat yang cukup.

Berdasarkan latar belakang dan permasalahan di atas, maka perumusan masalah dalam penelitian ini adalah: apakah sifat fisis dan mekanis dari material komposit serat rami dengan matriks polyester, dengan panjang serat yang berbeda-beda dapat dimafaatkan sebagai bahan teknik nonmetal yang digunakan sebagai bahan alternatif. Proses pembuatan dengan cara hand lay up dengan penekanan secara manual menggunakan kaca sebagai cetakan dan penekanan yang terbuat dari plat besi.

Pengujian komposit yang dilakukan berupa uji kekuatan tarik, uji kekuatan impak, dan foto patahan struktur makro, foto strutur mikro. Hal ini dilakukan karena produk komposit bisa dibuat sebagai partisi, atau meja/bangku atau casing yang sangat relevan terhadap beban impak dan beban tarik-tekan. Struktur makro dan mikro, untuk mengetahui kecenderungan fenomena perpatahan apa yang mungkin terjadi.

\section{TINJAUAN PUSTAKA DAN TEORI}

Komposit yang merupakan penggabungan dua atau lebih material secara makro sekarang ini pengunaannya semakin meningkat seiring dengan banyaknya penelitian yang dilakukan untuk memperbanyak variasi dan pemanfaatannya. Tujuan utama adanya penggabungan dalam bidang engineering yaitu hasil dari pengabungan itu harus dapat diaplikasikan untuk mengatasi permasalahan yang berkembang saat ini atau paling tidak harus sesuai dengan kebutuhan perencanaan suatu komponen struktur.

Komposit terdiri dari dua atau lebih material berbeda yang begabung sebagai suatu kombinasi yang menyatu. Jadi, beton bertulang merupakan komposit yang terbuat dari batang baja di dalam suatu matriks beton. Sama halnya, berbagai badan suatu perahu layar dibuat 
dari plastik yang diperkuat serat (FRP), di mana serat biasanya adalah gelas dan plastiknya umumnya adalah poliester [1]. Komposit lainnya menjadi produk seperti baja berlapis-gelas untuk kompor dapur dan motor roket dengan serat aramid yang disusun dengan cermat sebagai penguat (Lawrence H. Van Vlack) [2]. Pada penelitian kali ini digunakan komposit berpenguat serat ramiuntuk digunakan sebagai bahan spare part dan perlengkapan balap karena selain kuat dan tahan pecah juga mudah dicari bahan-bahan tersebut.

Ray et al. (2001) melakukan perlakuan serat jute dengan larutan alkali 5\% selama 0 , 2, 4, 6, 8 jam yang dilanjutkan dengan pencucian dan penetralan alkali dengan asam asetat, serta pengeringan pada temperatur kamar selama 48 jam dan dioven pada suhu $100^{\circ} \mathrm{C}$ selama 6 jam. Reduksi berat serat terjadi selama perendaman $\mathrm{NaOH}$ hingga 2 jam, setelah itu berat serat relatif konstan. Perkembangan kristalinitas serat jute meningkatkan modulus elastisitasnya sebesar 12\%, 68\%, dan 79\% setelah perlakuan alkali selama 4, 6, 8 jam.

\section{Bahan Matriks}

Plastik, serat, film, dan sebagainya yang biasa digunakan dalam kehidupan seharihari, mempunyai berat molekul di atas 10.000. Bahan dengan berat molekul yang besar itu disebut polimer, mempunyai sifat-sifat dan struktur yang rumit, disebabkan oleh jumlah atom pembentuk yang jauh lebih besar dibandingkan dengan senyawa yang berat atomnya rendah. Matrik yang digunakan dalam komposit adalah harus mampu meneruskan beban sehingga serat harus bisa melekat pada matrik dan kompatibel antara serat dan matrik artinya tidak ada reaksi yang mengganggu.

\section{Serat}

Serat atau fiber dalam bahan komposit berperan sebagai bagian utama yang menahan beban, sehingga besar kecilnya kekuatan bahan komposit sangat tergantung dari kekuatan serat pembentuknya. Semakin kecil bahan (diameter serat mendekati ukuran kristal) maka semakin kuat bahan tersebut, karena minimnya cacat pada material.

Tabel 1 Beberapa sifat-sifat serat baik natural fibre maupun sintetis fibre [3]

\begin{tabular}{lc}
\hline \multicolumn{1}{c}{ Jenis/Sifat } & Berat Jenis \\
\hline Kapas & $1,54 \mathrm{gr} / \mathrm{cm}^{3}$ \\
Wol & $1,32 \mathrm{gr} / \mathrm{cm}^{3}$ \\
Rayon & $1,50-1,52 \mathrm{gr} / \mathrm{cm}^{3}$ \\
Kevlar & $1,44 \mathrm{gr} / \mathrm{cm}^{3}$ \\
Sutra & $1,33-1,45 \mathrm{gr} / \mathrm{cm}^{3}$ \\
Vinilon & $1,26-1.30 \mathrm{gr} / \mathrm{cm}^{3}$ \\
Gelas (Jenis E) & $2,54 \mathrm{gr} / \mathrm{cm}^{3}$ \\
Nilon 66 & $300-502 \mathrm{gr} / \mathrm{cm}^{3}$ \\
\hline
\end{tabular}

\section{Bahan Tambahan}

Bahan tambahan utama adalah katalis (hardener). Katalis berfungsi memulai dan mempersingkat reaksi curing (mengerasnya cairan resin). Semakin banyak katalis reaksi curing akan semakin cepat, tetapi kelebihan katalis juga akan menimbulkan panas pada saat curing dan bisa merusak produk yang dibuat, yaitu menjadikan bahan komposit getas/rapuh. Oleh karena itu pemberian katalis dibatasi kira-kira 1\%-2\% dari berat resin. 


\section{Perlakuan Alkali (NaOH)}

Sifat alami serat adalah hyrophilic, yaitu suka terhadap air berbeda dari polimer yang hidrophilic. Pengaruh perlakuan alkali terhadap sifat permukaan serat alam selulosa telah diteliti dimana kandungan optimum air mampu direduksi sehingga sifat alami hidropholic serat dapat memberikan ikatan interfecial dengan matrik secra optimal (Bismarck et al. 2002).

Salah satu indikator yang digunakan untuk menunjukkan kebasaan adalah lakmus merah. Bila lakmus merah dimasukkan ke dalam larutan basa maka berubah menjadi biru.

\section{Kekuatan Impact $[4,5]$}

$$
\mathrm{E}_{\text {serap }}=\mathrm{G} \times \mathrm{R}(\operatorname{Cos} \beta-\operatorname{Cos} \alpha)
$$

Dimana:

$\mathrm{G} \quad=$ Berat beban/pembentur $(\mathrm{N})$

$\mathrm{R} \quad=$ Jari-jari putar ke titik berat pembentur $(\mathrm{m})$

$\mathrm{E}_{\text {serap }}=$ Energi yang terserap $(\mathrm{J})$

$$
\mathrm{HI}=\frac{E_{\text {serap }}}{\mathrm{A}}
$$

Dimana:

$\mathrm{HI}=$ harga impak $\left(\mathrm{J} / \mathrm{mm}^{2}\right)$

$\mathrm{E}_{\text {serap }}=$ Energi yang terserap $(\mathrm{J})$

$\mathrm{A}^{\text {serap }}=$ Luas di bawah takik $\left(\mathrm{mm}^{2}\right)$

\section{Kekuatan Tarik}

Besarnya nilai modulus elastisitas komposit yang juga merupakan perbandingan antara tegangan dan regangan pada daerah proporsional dapat dihitung dengan persamaan:

$$
\mathrm{E}=\sigma / \varepsilon
$$

\section{Dimana:}

$\mathrm{E} \quad=$ Modulus elastisitas tarik $(\mathrm{MPa})$

$\sigma \quad=$ Kekuatan tarik $(\mathrm{MPa})$

$\varepsilon \quad=$ Regangan $(\mathrm{mm} / \mathrm{mm})$

Besarnya regangan adalah jumlah pertambahan panjang karena pembebanan dibandingkan dengan panjang daerah ukur (gage length). Nilai regangan ini adalah regangan proporsional yang didapat dari garis. Proporsional pada grafik tegangan-regangan hasil uji tarik komposit.

$$
\varepsilon=\Delta \mathrm{L} / \mathrm{L}
$$

Dimana:
$\Delta \mathrm{L} \quad=$ pertambahan panjang $(\mathrm{mm})$
$\mathrm{L} \quad=$ panjang daerah ukur (gage length), $\mathrm{mm}$ 


\section{TUJUAN PENELITIAN DAN MANFAAT PENELITIAN}

\section{Tujuan Penelitian}

Tujuan dari penelitian ini antara lain:

1. Mengetahui kekuatan tarik, dan kekuatan impact dari komposit serat rami dengan perlakuan alkali selama 2, 4, 6, dan 8 jam.

2. Meneliti jenis-jenis patahan yang dihasilkan dari pengujian tarik dan pengujian impact.

3. Sebagai acuan baru untuk mengembangkan bahan komposit yang lain.

4. Untuk mengetahui foto makro pada jenis/bentuk patahan dan melihat foto struktur mikro penampang bahan uji.

\section{Manfaat Penelitian}

Hasil penelitian ini diharapkan mampu memberikan inspirasi dan menjadi:

1. Acuan akan lahirnya penelitian berikutnya.

2. Untuk pengembangan ilmu pengetahuan dan industri.

3. Mengetahui sifat fisis dan mekanis.

\section{METODOLOGI DAN PELAKSANAAN PENGUJIAN}

Diagram Alir

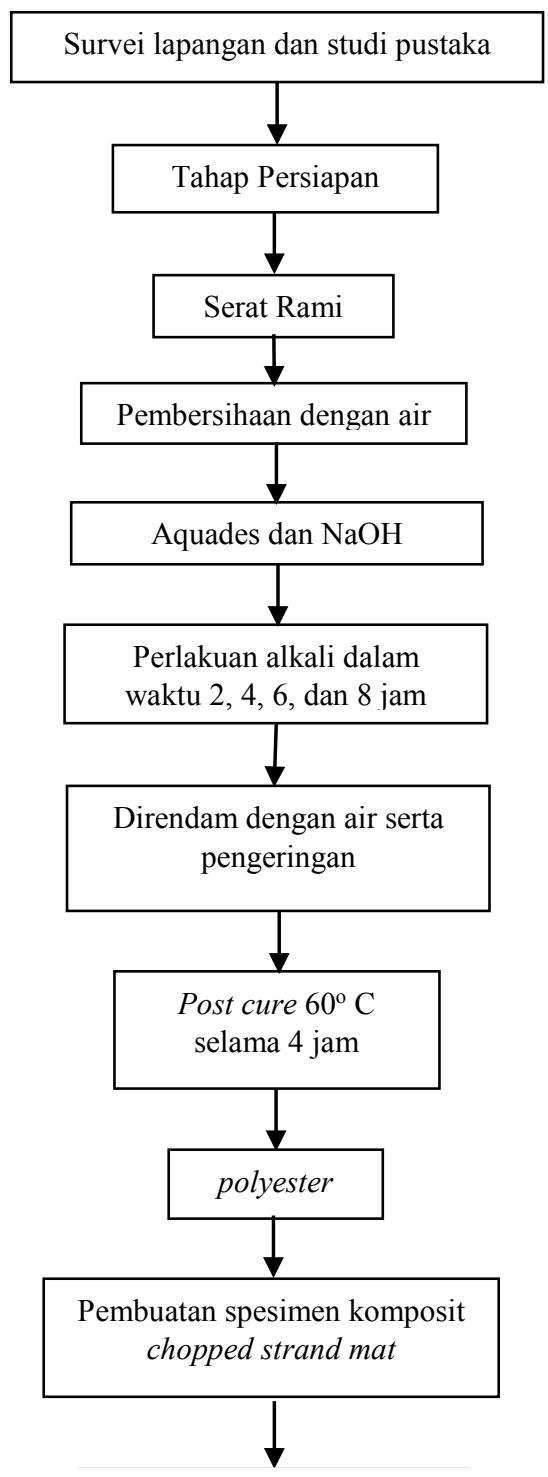




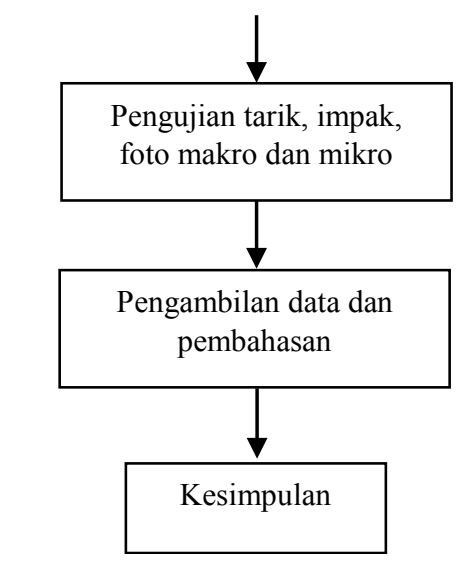

Gambar 1. Diagram alir penelitian

\section{Penyiapan Pembuatan Benda Uji}

Bahan yang digunakan dalam penelitian ini adalah sebagai berikut:

1. Serat rami

Tali tambang yang terbuat dari rami yang masih baru diurai satu per satu seratnya, kemudian diambil seratnya dengan cara menggunakan sisir, dicuci, dan dikeringkan.

Serat tersebut lalu dipotong $60 \mathrm{~mm}$ kemudian serat tersebut direndam dalam $\mathrm{NaOH}$ selama 2, 4, 6, dan 8 jam.

2. Polyester

Terdiri dari dua jenis resin $(1 \mathrm{~kg})$ dan katalis $(200 \mathrm{ml})$. Matrik yang digunakan pada penelitian ini adalah jenis polyester yaitu polyester 108 yang berwarna bening dan katalis yang digunakan adalah MEKPO (metil etil keton peroksida).

3. $\mathrm{NaOH}$

$\mathrm{NaOH}$ digunakan untuk menghilangkan lignin pada serat dengan kadar 5\% $\mathrm{NaOH}$.

4. Timbangan digital, untuk menimbang serat serabut rami dan resin polyester digunakan timbangan digital mini seri M200 (max 200gr).

5. Cetakan benda uji cetakan yang digunakan terbuat dari kaca dengan ketebalan $4 \mathrm{~mm}$.

6. Alat bantu lain berupa gelas ukur, penggaris, cutter, kit mobil, lem castol, sendok, pisau.

\section{Pengujian Spesimen}

Pengujian spesimen yang dilakukan meliputi uji tarik (ASTM D 638 - 03) dan uji impact (ASTM D 256 - 03) [6], pengamatan struktur makro patahan setelah uji tarik dan pengamatan struktur mikro pada patahan uji impact.

\section{Pengujian Komposit}

Pengujian yang dilakukan pada penelitian ini antara lain pengujian tarik, pengujian impak, dan foto makro patahan, dan struktur mikro.

\section{Pengujian Tarik}

Pengujian tarik dilakukan untuk mengetahui besarnya kekuatan tarik dari bahan komposit. Pengujian dilakukan dengan mesin uji "Universal Testing Machine”. Spesimen pengujian tarik dibentuk menurut standar ASTM D 638-03 yang ditunjukkan pada gambar berikut: 


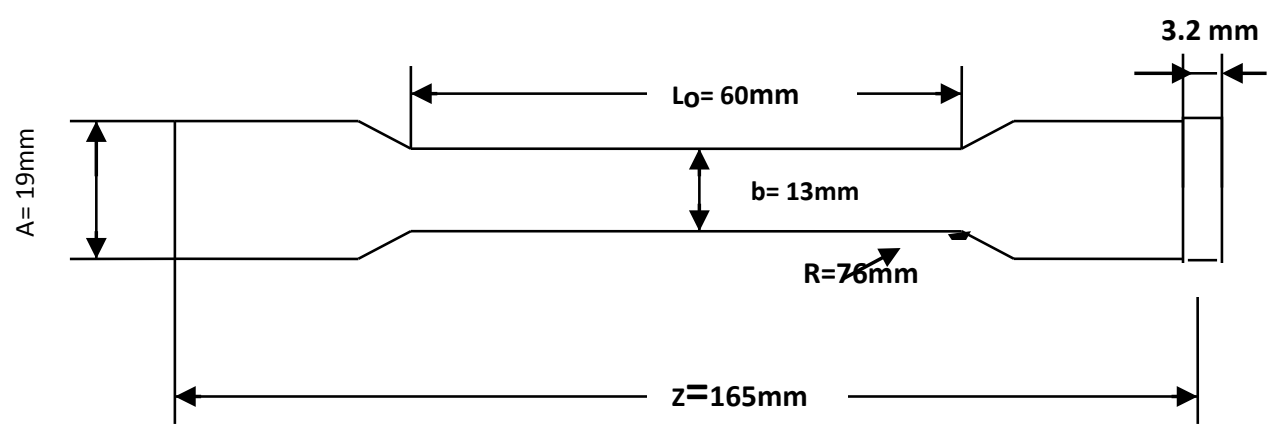

Gambar 2. Dimensi benda pengujian tarik ASTM D 638 - 03 [6]

\section{Pengujian Impact}

Untuk mengetahui ketahanan benda terhadap keadaan patah, maka digunakan metode pengujian impact charphy. Batang uji charphy mempunyai luas penampang lintang bujur

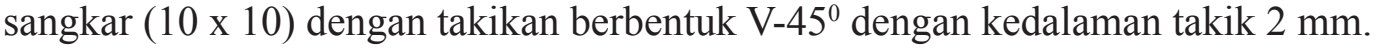
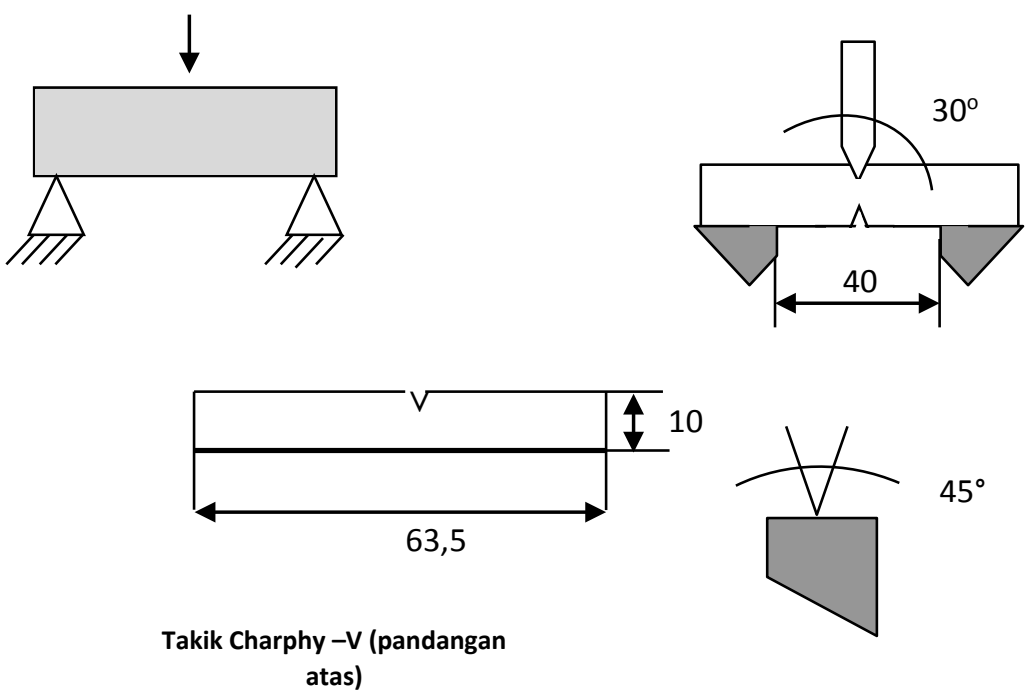

Gambar 3. Dimensi spesimen pengujian impact ASTM D 256-03 [6]

\section{HASIL PENELITIAN DAN PEMBAHASAN}

\section{Pengujian Tarik}

Pengujian tarik dilakukan dengan membuat spesimen yang disesuaikan dengan standar pengujian tarik ASTM 638-03.

Tabel 2. Data dimensi spesimen untuk pengujian tarik serat rami

\begin{tabular}{|c|c|c|c|c|c|}
\hline $\begin{array}{c}\text { Jenis } \\
\text { Komposit }\end{array}$ & $\begin{array}{c}\text { No } \\
\text { Spesimen }\end{array}$ & $\begin{array}{r}\text { Lebar } \\
(\mathrm{mm})\end{array}$ & $\begin{array}{l}\text { Tebal } \\
(\mathrm{mm})\end{array}$ & $\begin{array}{c}\text { Panjang Awal } \\
(\mathrm{mm})\end{array}$ & $\begin{array}{l}\text { Luas } \\
\left(\mathrm{mm}^{2}\right)\end{array}$ \\
\hline \multirow{3}{*}{$\begin{array}{l}\text { Perlakuan alkali } \\
\text { selama } 2 \text { jam }\end{array}$} & 1 & 13 & 6 & 60 & 780 \\
\hline & 2 & 13 & 6 & 60 & 780 \\
\hline & 3 & 13 & 6 & 60 & 780 \\
\hline \multirow{3}{*}{$\begin{array}{l}\text { Perlakuan alkali } \\
\text { selama } 4 \text { jam }\end{array}$} & 1 & 13 & 6 & 60 & 780 \\
\hline & 2 & 13 & 6 & 60 & 780 \\
\hline & 3 & 13 & 6 & 60 & 780 \\
\hline
\end{tabular}




\begin{tabular}{|c|c|c|c|c|c|}
\hline \multirow{3}{*}{$\begin{array}{l}\text { Perlakuan alkali } \\
\text { selama } 6 \text { jam }\end{array}$} & 1 & 13 & 6 & 60 & 780 \\
\hline & 2 & 13 & 6 & 60 & 780 \\
\hline & 3 & 13 & 6 & 60 & 780 \\
\hline \multirow{3}{*}{$\begin{array}{l}\text { Perlakuan alkali } \\
\text { selama } 8 \text { jam }\end{array}$} & 1 & 13 & 6 & 60 & 780 \\
\hline & 2 & 13 & 6 & 60 & 780 \\
\hline & 3 & 13 & 6 & 60 & 780 \\
\hline
\end{tabular}

Tabel 3 Hasil pengujian tarik komposit serat rami tanpa perlakuan alkali

\begin{tabular}{lcccccc}
\hline $\begin{array}{c}\text { Jenis } \\
\text { Komposit }\end{array}$ & $\begin{array}{c}\text { No } \\
\text { Spesimen }\end{array}$ & $\begin{array}{c}\text { Kekuatan } \\
\text { Tarik }(\sigma) \\
(\mathrm{Mpa})\end{array}$ & $\begin{array}{c}\text { Kekuatan } \\
\text { Tarik Rata- } \\
\text { Rata (Mpa) }\end{array}$ & $\begin{array}{c}\text { Regangan } \\
(\varepsilon)\end{array}$ & $\begin{array}{c}\text { Modulus } \\
\text { Elastisitas } \\
(\mathrm{Mpa})\end{array}$ & $\begin{array}{c}\text { Modulus } \\
\text { Elastisitas } \\
\text { Rata-Rata } \\
(\mathrm{Mpa})\end{array}$ \\
\hline Panjang & 1 & 24.70 & & 0.005 & 4940 & \\
Serat & 2 & 26.40 & 25.87 & 0.0042 & 6285.71 & 5846.67 \\
$50 \mathrm{~mm}$ & 3 & 26.52 & & 0.0042 & 6324.3 & \\
\hline
\end{tabular}

Tabel 4 Hasil pengujian tarik komposit serat rami

\begin{tabular}{|c|c|c|c|c|c|c|}
\hline Jenis Komposit & $\begin{array}{c}\text { No } \\
\text { Spesimen }\end{array}$ & $\begin{array}{c}\text { Kekuatan } \\
\text { Tarik }(\sigma) \\
\quad(\mathrm{Mpa})\end{array}$ & $\begin{array}{l}\text { Kekuatan } \\
\text { Tarik Rata- } \\
\text { Rata (Mpa) }\end{array}$ & $\begin{array}{l}\text { Regangan } \\
(\varepsilon)\end{array}$ & $\begin{array}{l}\text { Modulus } \\
\text { Elastisitas } \\
\text { (Mpa) }\end{array}$ & $\begin{array}{c}\text { Modulus } \\
\text { Elastisitas } \\
\text { Rata-Rata } \\
\text { (Mpa) }\end{array}$ \\
\hline \multirow{3}{*}{$\begin{array}{l}\text { Perlakuan alkali } \\
\text { selama } 2 \text { jam }\end{array}$} & 1 & 24.56 & \multirow{3}{*}{33.1} & 0.90 & 27.29 & \multirow{3}{*}{2743.15} \\
\hline & 2 & 34.53 & & 0.70 & 49.05 & \\
\hline & 3 & 39.95 & & 0.049 & 8153.1 & \\
\hline \multirow{3}{*}{$\begin{array}{l}\text { Perlakuan alkali } \\
\text { selama } 4 \text { jam }\end{array}$} & 1 & 36.80 & \multirow{3}{*}{34.1} & 0.0205 & 1795.1 & \multirow{3}{*}{1653.63} \\
\hline & 2 & 31.95 & & 0.0238 & 1342.4 & \\
\hline & 3 & 33.55 & & 0.0184 & 1823.4 & \\
\hline \multirow{3}{*}{$\begin{array}{l}\text { Perlakuan alkali } \\
\text { selama } 6 \text { jam }\end{array}$} & 1 & 36 & \multirow{3}{*}{39.41} & 0.0216 & 1666.7 & \multirow{3}{*}{1707.23} \\
\hline & 2 & 39.73 & & 0.0294 & 1351.4 & \\
\hline & 3 & 42.50 & & 0.0202 & 2103.9 & \\
\hline \multirow{3}{*}{$\begin{array}{l}\text { Perlakuan alkali } \\
\text { selama } 8 \text { jam }\end{array}$} & 1 & 42.56 & \multirow{3}{*}{41.9} & 0.0227 & 1878.8 & \multirow{3}{*}{2006.38} \\
\hline & 2 & 42.52 & & 0.0212 & 1992.9 & \\
\hline & 3 & 40.80 & & 0.019 & 2147.4 & \\
\hline
\end{tabular}




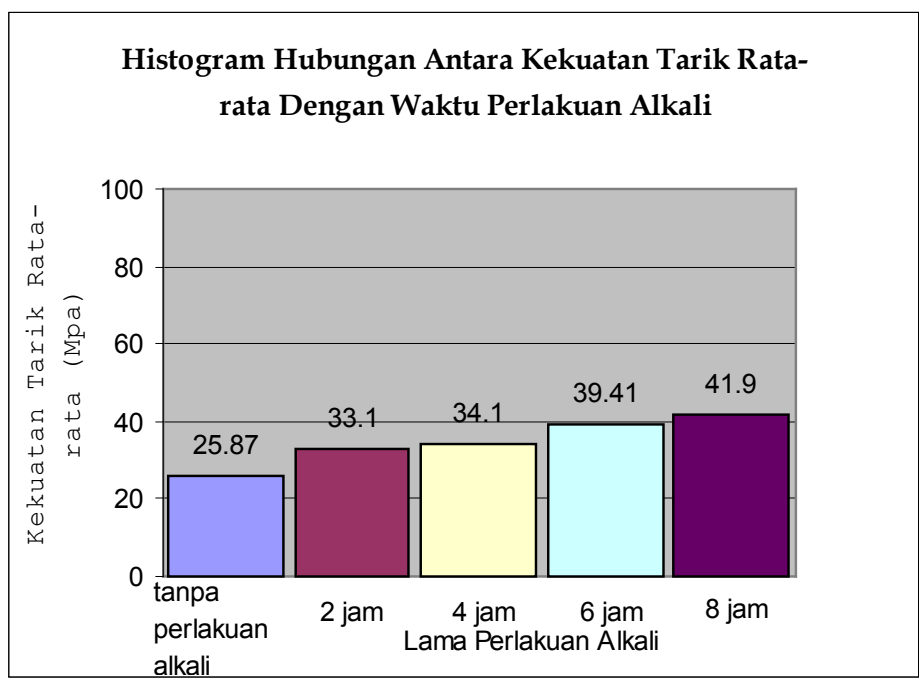

Gambar 4 Histogram hubungan antara kekuatan tarik rata-rata dengan waktu perlakuan alkali

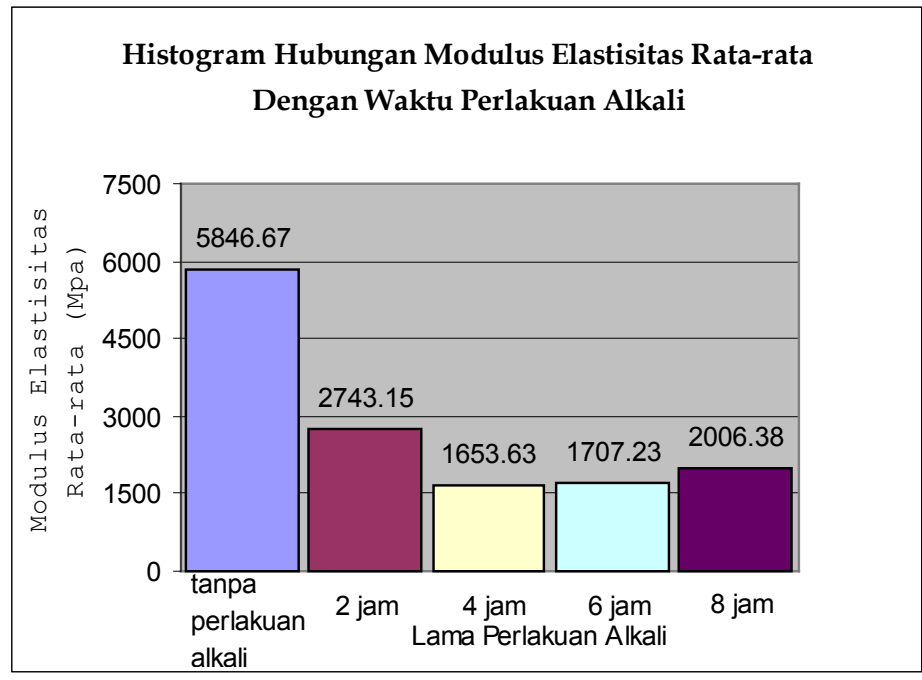

Gambar 5 Histogram hubungan antara modulus elastisitas rata-rata dengan eaktu perlakuan alkali

Dari data-data yang telah diperoleh tersebut komposit dengan serat rami dengan perlakuan alkali selama 2, 4, 6, dan 8 mempunyai kekuatan tarik rata-rata masing-masing, yaitu 33.01 Mpa, 34.1 Mpa, 39.41 Mpa, dan 41.9 Mpa. Dan serat tanpa perlakuan alkali mempunyai kekuatan tarik rata-rata sebesar 25.87 Mpa. Jadi dapat disimpulkan bahwa kekuatan tarik untuk komposit serat rami dengan perlakuan alkali 8 jam lebih tinggi dibandingkan dengan komposit serat rami tanpa perlakuan alkali. Hal ini disebabkan karena serat yang sudah dialkali akan mengembang oleh alkali dan kekuatan tidak menurun yang mempengaruhi kekuatan tarik, dan juga ikatan serat dan matrik semakin kuat.

Pada data pengujian tarik komposit serat rami menunjukkan bahwa komposit dengan perlakuan alkali dalam waktu 2 jam mempunyai modulus elasitisitas rata-rata paling tinggi, yaitu sebesar $2743.15 \mathrm{MPa}$, dan terkecil pada komposit dengan perlakuan alkali selama 4 jam, yaitu sebesar 1653.63 MPa. Agar material penguat menanggung sebagian besar beban, penguat harus memiliki modulus elastisitas yang lebih tinggi dari pada matriknya (Lawrence H Van Vlack). 


\section{Pengujian Impact}

Untuk spesimen komposit untuk masing-masing spesimen komposit yaitu serat serabut kelapa dengan panjang $60 \mathrm{~mm}$ dengan perlakuan alkali selama 2, 4, 6, dan 8 jam mengacu pada standar ASTM D256-03.

Tabel 5 Data dimensi spesimen uji impact komposit serat rami

\begin{tabular}{|c|c|c|c|c|c|c|}
\hline $\begin{array}{c}\text { Jenis } \\
\text { Komposit }\end{array}$ & $\begin{array}{c}\text { No } \\
\text { Spesimen }\end{array}$ & $\begin{array}{l}\text { Lebar } \\
(\mathrm{mm})\end{array}$ & $\begin{array}{l}\text { Tebal } \\
(\mathrm{mm})\end{array}$ & $\begin{array}{l}\text { Kedalaman } \\
\text { Takik } \\
(\mathrm{mm})\end{array}$ & $\begin{array}{c}\text { Tinggi Bawah } \\
\text { Takik } \\
(\mathrm{mm})\end{array}$ & $\begin{array}{c}\text { Penampang } \\
\text { Bawah Takik } \\
\left(\mathrm{mm}^{2}\right)\end{array}$ \\
\hline \multirow{3}{*}{$\begin{array}{l}\text { Perlakuan } \\
\text { alkali selama } \\
2 \text { jam }\end{array}$} & 1 & 9.8 & 10 & 2 & 8 & 78.4 \\
\hline & 2 & 10 & 10 & 2 & 8 & 80 \\
\hline & 3 & 9.8 & 10 & 2 & 8 & 78.4 \\
\hline \multirow{3}{*}{$\begin{array}{l}\text { Perlakuan } \\
\text { alkali selama } \\
4 \text { jam }\end{array}$} & 1 & 9.8 & 10 & 2 & 8 & 78.4 \\
\hline & 2 & 10 & 10 & 2 & 8 & 80 \\
\hline & 3 & 9.9 & 10 & 2 & 8 & 79.2 \\
\hline \multirow{3}{*}{$\begin{array}{l}\text { Perlakuan } \\
\text { alkali selama } \\
6 \text { jam }\end{array}$} & 1 & 10 & 10 & 2 & 8 & 80 \\
\hline & 2 & 10 & 10 & 2 & 8 & 80 \\
\hline & 3 & 9.9 & 10 & 2 & 8 & 79.2 \\
\hline \multirow{3}{*}{$\begin{array}{l}\text { Perlakuan } \\
\text { alkali selama } \\
8 \text { jam }\end{array}$} & 1 & 10 & 10 & 2 & 8 & 80 \\
\hline & 2 & 10 & 10 & 2 & 8 & 80 \\
\hline & 3 & 10 & 10 & 2 & 8 & 78.4 \\
\hline
\end{tabular}

Tabel 6 Data hasil pengujian impact komposit serat rami tanpa perlakuan alkali

\begin{tabular}{lcccccc}
\hline $\begin{array}{c}\text { Jenis } \\
\text { Komposit }\end{array}$ & $\begin{array}{c}\text { No } \\
\text { Spesimen }\end{array}$ & $\begin{array}{c}\text { Friksi } \\
(\mathrm{J})\end{array}$ & $\begin{array}{c}\mathrm{A}^{\mathrm{o}} \\
\left(\mathrm{mm}^{2}\right)\end{array}$ & $\begin{array}{c}\text { Energi yang } \\
\text { Diserap } \\
(\mathrm{J})\end{array}$ & $\begin{array}{c}\text { Harga Impak } \\
\left(\mathrm{J} / \mathrm{mm}^{2}\right)\end{array}$ & $\begin{array}{c}\text { Harga Impak } \\
\text { Rata-Rata } \\
\left(\mathrm{J} / \mathrm{mm}^{2}\right)\end{array}$ \\
\hline Panjang & 1 & 2.5 & 78.4 & 5 & 0.0875 & \\
Serat & 2 & 2.5 & 80 & 5.5 & 0.0812 & 0.0877 \\
$50 \mathrm{~mm}$ & 3 & 2.5 & 78.4 & 5 & 0.0946 & \\
\hline
\end{tabular}

Tabel 7 Data hasil pengujian impact komposit serat rami

\begin{tabular}{|c|c|c|c|c|c|c|}
\hline $\begin{array}{c}\text { Jenis } \\
\text { Komposit }\end{array}$ & $\begin{array}{c}\text { No } \\
\text { Spesimen }\end{array}$ & $\begin{array}{l}\text { Friksi } \\
(\mathrm{J})\end{array}$ & $\begin{array}{c}\mathrm{A}^{\circ} \\
\left(\mathrm{mm}^{2}\right)\end{array}$ & $\begin{array}{c}\text { Energi yang } \\
\text { diserap } \\
(\mathrm{J})\end{array}$ & $\begin{array}{l}\text { Harga Impak } \\
\qquad\left(\mathrm{J} / \mathrm{mm}^{2}\right)\end{array}$ & $\begin{array}{c}\text { Harga Impak } \\
\text { Rata-Rata } \\
\left(\mathrm{J} / \mathrm{mm}^{2}\right)\end{array}$ \\
\hline Perlakuan alkali & 1 & 2.5 & 78.4 & 5.7 & 0.0717 & \\
\hline selama & 2 & 2.5 & 80 & 5.6 & 0.0704 & 0.0683 \\
\hline $2 \mathrm{jam}$ & 3 & 2.5 & 78.4 & 6 & 0.0629 & \\
\hline Perlakuan alkali & 1 & 2.5 & 78.4 & 5 & 0.0755 & \\
\hline selama & 2 & 2.5 & 80 & 5 & 0.0629 & 0.0725 \\
\hline 4 jam & 3 & 2.5 & 79.2 & 6.3 & 0.0792 & \\
\hline Perlakuan alkali & 1 & 2.5 & 80 & 5.5 & 0.0692 & \\
\hline selama & 2 & 2.5 & 80 & 5.4 & 0.0692 & 0.0671 \\
\hline $6 \mathrm{jam}$ & 3 & 2.5 & 79.2 & 5 & 0.0629 & \\
\hline Perlakuan alkali & 1 & 2.5 & 80 & 6 & 0.0629 & \\
\hline selama & 2 & 2.5 & 80 & 5.7 & 0.0717 & 0.0671 \\
\hline 8 jam & 3 & 2.5 & 78.4 & 5.3 & 0.0667 & \\
\hline
\end{tabular}




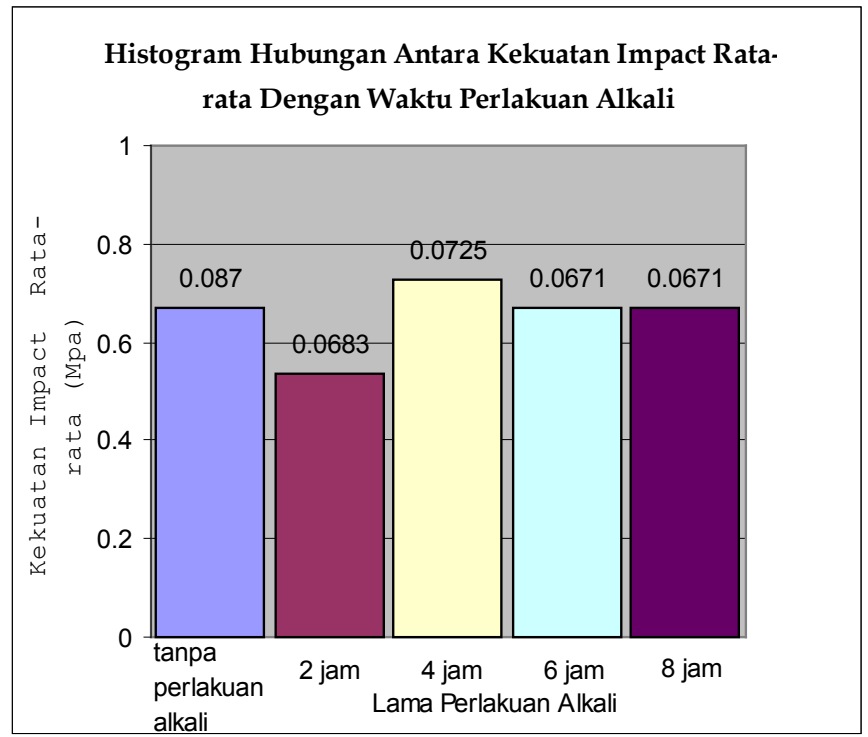

Gambar 6 Histogram hubungan kekuatan impact rata-rata komposit serat rami terhadap waktu perlakuan alkali

Untuk hasil pengujian impact, perbedaan antara harga impact rata-rata dari komposit disebabkan oleh beberapa hal. Antara lain disebabkan karena kekuatan komposit yang kurang merata dan distribusi serat yang kurang merata sehingga energi yang diserap menjadi lebih kecil. Sedangkan patahan yang terjadi adalah patahan getas.

Harga impact rata-rata yang tertinggi adalah komposit serat rami tanpa perlakuan alkali yaitu sebesar $0.0877 \mathrm{~J} / \mathrm{mm}^{2}$ sedangkan yang terendah adalah komposit serat rami dengan perlakuan alkali selama 6 dan 8 jam yaitu mempunyai harga impact rata-rata sebesar 0.0671 $\mathrm{J} / \mathrm{mm}^{2}$ dan $0.0671 \mathrm{~J} / \mathrm{mm}^{2}$.

\section{KESIMPULAN DAN SARAN}

\section{Kesimpulan}

Dari hasil penelitian dan analisis pengujian serta pembahasan data yang diperoleh, dapat disimpulkan:

1. Kekuatan tarik rata-rata tertinggi adalah komposit dengan perlakuan alkali 8 jam yaitu sebesar 41.9 Mpa.

2. Modulus elastisitas rata-rata tertinggi adalah pada komposit dengan perlakuan alkali 2 jam yaitu sebesar 2743.15 Mpa.

3. Besarnya kekuatan impact rata-rata tertinggi adalah pada komposit dengan perlakuan alkali 4 jam yaitu sebesar $0.0725 \mathrm{~J} / \mathrm{mm}^{2}$.

\section{Saran}

Dari hasil proses percetakan ada beberapa hal yang perlu diperhatikan, diantaranya:

1. Proses penekanan yang dilakukan terhadap komposit seharusnya menggunakan alat yang lebih baik sehingga dapat diperoleh penekanan yang lebih maksimal.

2. Meminimalkan keberadaan rongga udara ( void) pada komposit yang akan dibuat sehingga akan menaikkan kemampuannya.

3. Dalam melakukan pembuatan benda uji hendaknya memakai alat pengaman, karena bahan benda uji merupakan bahan kimia.

4. Pada proses penuangan matrik kedalam serat harus merata agar serat benar-benar terbungkus oleh matrik, sehingga dapat meminimalkan terjadinya void. 
5. Dalam melakukan pengujian hendaknya dilakukan sendiri agar kita mengetahui proses pengujian tersebut.

\section{DAFTAR PUSTAKA}

[1] ASTM. 1990. Standart and Literature References for Composite Materials, 2d ed., Philadelphia. PA: American Society for Testing and Materials.

[2] Van Vlack. 1992. Ilmu dan Teknologi Bahan, Edisi ke-5. Jakarta: Erlangga.

[3] Surdia, T. dan S. Saito. 1999. Pengetahuan Bahan Teknik, Cetakan ke-4. Jakarta: Pradnya Paramita.

[4] Dieter, George E.; Djaprie, Sriati. 1993. Metalurgi Mekanik, Edisi ke-3. Jakarta: Erlangga.

[5] Groenendijk, J. Van der Line, Ir. Sobandi Sacrhri. 1996. Pengujian Materil. Jakarta: Binacipta.

[6] 1958. ASM Hand Book Comitte Metallography and Microstructures. American Society for Metal. 